\title{
EFFECTIVENESS OF AN INTEGRATED APPROACH TO TREAT AUTISTIC KIDS CASE STUDY
}

\author{
Dr.Nader Ahmad Jaradat \\ Associate professor Al-Zarqa University-Jordan. \\ Faculty of Education. \\ Jaradat62@hotmail.com \\ najaradat@zu.edu.jo
}

\section{Abstract}

This present study is interested in the effectiveness at an integrated program in the treatment of autism. The sample of the study is one autistic child, the sample was chosen in a deli bate manner.

The question of the study is: How effective is the integrated program in the treatment of autism? The researcher has designed the integrated program, the results should the effectiveness of the program in the treatment of autism after the application of the program.

The results have been discussed in the aspect of benign harmony with the previous studies a lot of recommendations have been introduced to help this category to cope with being disabled of (handicapped) and overcome the consequences.

The effectiveness of an integrated program to treat Autism-A case Study.

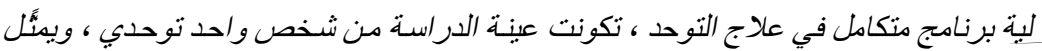

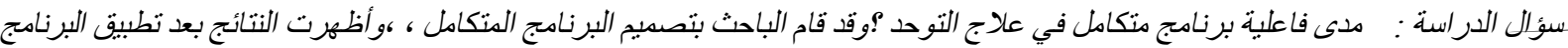

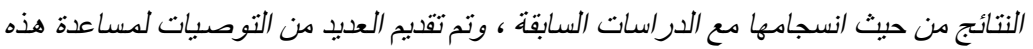

$$
\begin{aligned}
& \text { الفئة على التكيف مع الإعاقة وتجاوز تبعاتها. } \\
& \text { كلمات مفتاحية : التوحد ، البرنامج الدتكامل . }
\end{aligned}
$$

\section{Introduction and Background:}

Autism is considered one of the most complicated social phenomenon that forces societies, scientists and researchers all over the world Autism case is recently discovered, compared with other disorders known. It is not considered psychological disease. It is a developmental disorder that affects different sides of the growth. (Sarawak and others 2015)

The interest in autistic children has relatively increased in the last decade in the Arab countries. Leo kennels considered to be. The first person who pointed out that autism is a disability which takes place at childhood. It is diagnosed it specifically after the child is three years old when symptoms of autism appears some of these symptoms are $\mathrm{He} / \mathrm{She}$ does not respond to his/her name another symptoms is the inability to communicate visually with others and the inability to play actively and the disability of limitation. When these factors appear the child is exposed to autism, so the child and his family must receive support. Theeb (2013).

The autistic child suffers of being unable to fulfill his daily needs and the skill of taking care of himself and the 
independence of fulfilling his daily needs. Alone he is always in need of someone to take care of him. He needs the help of others to do his personal needs.

(Al-Kha'ran 2015). Inspite of the different procedures available for different treatment which was designed by researchers there is still a more complicated problem in performing daily skills and the skills of self-taking care and the ordinary phenomenon that the autistic child needs adults to help him in doing his daily needs of clothing, drinking and feeding etc. (Dagestani 2011).

The study of Hus Bal, et al, (2015) which aimed to know the social behavior directed to autistic and mentally related children .The result of the study explained that autistic children suffer from the lack of visual communication and exchange by the eyes with others compared with mentally related children. The study of Unload Varna (2012) agrees with them the study indicated that autistic children badly need treatment programs because they suffer from behavioral disorders, as many of those who have special needs, so that they prefer the chaos of mixed voices or the withdrawal from social situations in a way showing their mentally restarted mates who prefer the mother's voice. The researcher indicates that symptoms of autistic kids are with draw from social situations as assured by the results of (Ammar's 2005).
Autistic children have the tendency to withdraw and they are non-interactive socially and are negative towards others. That they don't show any desire to share children their games and toys . They don't interact with their fathers and they avoid any family gatherings, they have got a slow response to environmental matters .They have general weakness in social activities. Meanwhile after the researchers see that withdrawal doesn't apply on all cases and this what Al-Zahrani confirmed in his study that some autistic children may got close to familiar persons and the love of games that require physical contact when some of them might sit in that person's room and enjoy hugging him and there are some children who may suffer a sharp worry if a dear person departed (AlQahtani 2015). Indicates that autistic child had a disability in many behavioral aspects which ordinary children of his age can perform. In the age of 5-10 years an autistic child can't perform works that an ordinary 2-year old child can or even less can perform and he can't take care of himself or protect himself or feed himself he needs someone to feed him or take off his clothes or putting them on. He may not care if he was given a toy to play with he will put it in his mouth or keeps on hitting it with his hands. It is popular for autistic kid night ruining and food problems as well as the inability to sleep $\rightarrow$ (Insomnia).

Many different studies considered programs and the ropy methods that is used with autistic kids-Behavioral amendment 
programs are considered as training programs that are used with autistic kids in order to train and qualify them such as improving skills programs to achieve independence, this method is considered among the best methods that proved great affect in dealing with autistic kids and the of qualifying them and leading them. (Dabbanna and Parish 2016).

But the behavioral treatment depends on the techniques of behavior management in order to get rid of any UN accepted behavior and the reduction of repeated activities and other forms of behavior reward and punishment is considered to be the main principle in this technique.

Reinforcement of positive behaviorthe reduction of negative behavior.

The success of behavioral treatment with these children led to encourage gaining social skills and communication skills and self-care and knowledge skills. Al-khofash 2013 sees that reinforces must be used when the child response is correct so that it is a reward for his response. There should be variety of reinforces. That they include social and material reinforces. Among that must important studies which used the behavioral adjustment approach with autistic children through the program is the study of Al-jarhi (2004) which aimed at making sure of the effectiveness of behavioral program to reduce aggressive behavior of autistic children .The result of the study explained the effectiveness the behavior program to reduce of aggressive behavior. According to the experimental group that was exposed to the program and the study of Al-Dawaideh ( 2013) that aimed at the recognition of effectiveness of adjustment methods of behavior to server in divided to adjust the autistic child, the results showed the effectiveness of behavior adjustment through the increase of communication and the reduction hyper activity. Thus the searcher sees that behavior direction depends on the principle of rereading which is the principle called upon by the law of good effect to Thorandeck so that the child is rewarded every that he does what is required from him so reinforcement is considered a basic element in the stability of cored response and the attempt to the continuity so the present study concentrated on using the mother of behavior adjustment and the use of reinforcement of all kinds social and material and variety of rewards so that the child won't are bored in addition to the use of simple punishment methods such as ignoring in order to dismiss unwanted behavior. some studies and psychological programs for autistic child so ( showee ( 2013) ) proved that traditional psychological treatment for autistic children, the concentration is upon the abin -psychological operations so that autisms refers to parent's failure and the cure may concentrate on an environment away from parent . so that the child could grow as an independent person it was discovered that this treatment is related with Childs language skills . some studies 
addressed the Childs daily life in improving the cases of autistic children so the program achieved positive results on the list of the four behavior appearances .

Which includes (emotional disorders , social disorder, language disorders and behavior patterns ) thus playing is considered to be a good material to solve some problems and behavior disorders or unrest for the autistic kid. Thus some studies concentrated upon him which works on the adjustment of behavior. among these studies ( Tawfiq 2012) the study aimed at the discovery of effectiveness of the program which contains different games in the treatment of behavior unrest ( disorders ) to the kids. The results showed the effectiveness of using games a note blereduction of aggressive behavior and introvert .

( khattab's study 2012 ) which aimed at preparing a cure program by using games to reduce the sharpness of some behavior disorder for autistic children so that the results ended that playing as all other psychological treatment methods it addresses the character as whole and affects it addresses it generally and Dagestan went to say that there is severe need to teach autistic children life skills, because it takes time and efforts to teach certain behavior by trainers and parents . so teaching the autistic kids daily skills is important and necessary for them to depend on themselves in the house or in the caring center . (Dagestan 2012 ). there are effective methods of teaching and training of life skills for autistic kids as working in small groups and brain storming, rule play, games and discussions - the study of Carthorse and Taylor addressed the importance of co-operation of parents and teacher in the effectiveness of gaining the autistic kid self - care and the care of mother to her child and raining him on how to take care of himself . this would enforce the level of the children's gaining of self -care skills ( Catothers.D.E,2004).

Many studies addressed the importance of different programs in the developing of different skills to autistic kids (Qassem's Abdl-Rahman 2007) . pointed out the importance effectiveness of recreational programs and its effect on the Development of self-care for mentally retarded children ( Qassem and abdalrahman2007).

(CAVKAYTUR , 2009 ) indicated the importance of operation between the healer and the parent $s$ in training of selfcare in particular and home skills for autistic kids . ( Gasal's study ) addressee, that the parent's participation in the coaching program, and training of how to deal with autistic kid is very important to develop the kid's pronunciation skills and non-pronunciation skills and self- care skills and the control of behavior problems and results of the study reached the existence of vital effect to parent's participation in coaching program and training in the growth of self - care and the reduction of autism symptoms to the 
individuals of the study sample (Gaza 2007) .

Thebe concluded in his study that the program that he prepared to develop social skills and communicative skills as well as self-independence in notable rates . Also reduced some adjustable behavior for autistic kids ( Theeb 2004 ) . in the light of these problems many studies recommended the need of presenting training programs for autistic kids in order to improve their skills . ( Salamah 2005 ) added that among the problems of food and drinks is the problem of sharp mood . the termination of eating curtain food or the insistence of serving the food himself or arranging the table in the same way without any change and among that factors that keep the child continuation of this behavior is the fear of parents that could lead to an attempt of change .

Which might lead to child's justifications but the inflexibility in serving food and arranging it couldn't be achieved in all situations and in all times so it becomes necessary to change the child's behavior to food and drinks to grantee a bigger or amount of flexibility so if is clear that necessity of training programs to develop the Development of different skills for autistic kids.

And since there was a seminar for training programs which try to develop these skills. The researcher is going to prepare a training program needed by autistic kids to develop their skills. And the use of a group of different techniques and methods (Models by using video tapes - Mission analysis guiding and reinforcement ) such as these methods . have effective influence in changing the behavior of autistic kids. Behavior approaches will be unlisted to adjust the behavior The researcher also sees that this big variety of treating methodologies for a large number of specialists in different area - The researcher also sees that this big variety in methodologies for treating autism disorders the care by a large number of specialists in different areas, and the success of some training methods and qualifying and educational and social interactions with one case of autistic kids doesn't necessarily mean it's success in all similar cases, because cache autistic which makes him different from the other autistic kids .

This also means that any treatment or qualifying followed to qualify a certain child doesn't necessarily mean that it will gain the same amount of plan success if it was applied on another child -Each child has his own circumstances and condition and abilities and degree of disability and he has his own training and qualifications methods and techniques .

From this point we see the importance of building and designing programs that meet the autistic child's needs . so this program came to meet the autistic child's needs and enter the feeling of independence and satisfaction to himself 
, to achieve and challenge obstacles and use the alternatives

Through these previous presentation , it is crystal clear for the researcher that most studies Arabic or foreign addressed individual programs and didn't address many sides as a whole or integrated . from this the researcher wanted to study an integrated program to treat autistic children which meets an important side and comprehensive for this category the problem of the study . the problem of the study is the large number of autistic children in society there are no programs which facilitate their independence even in the most simple matters . many of these children can't pay the cost of training in centers or corporation, or fees even reach them because of the far distance, in the light of the need of this category to special care and since they look at life in different way from others, their loot at life is influenced by their disability .And whatever support they gain from other . family or society and this category needs coaching and training services which help them to be independent and the agreement with life condition with the presence of the disability . the different skills for the autistic child one of cheimportent indicator of the good quality of the services and programs given this category. The satisfaction of individual and his feeling of happiness and the desire to live in order to achieve this target . the present study is trying know the effectives of the integrated program in the treatment of autisms, the study of a case and in particular the answer of the following question :

How far is the range of effectiveness of an integrated program case to treat autisms?

\section{a case study?}

the study hay pothouses, there are no statistical, indicative differences in $(0,05 \geq \mathrm{oc})$

between a averages of performance of the experimental sample on the dimension measure.

The importance of the study: the importance of the present study is beings :

- It is concerned with the early childhood stage which has got a great affection on the child life .

- It highlights the importance of care for this category .

- It also highlights the most important skills which help the autistic child to grow naturally .

- Draw the attention of researchers to design integrated programs for the different skills of the autistic child and developing them.

- The need of the autistic children for programs which intend to prepare them for life and self- dependence .

- The submitting of the integrated skills measurement to the autistic children .

- Submitting of program using educational activities and various 
behavior adjustments techniques to Development different skills for autistic children .

- Supply the centers of the preparation of training programs for this category with programs that may continue in the Development of different skill of the autistic child in the growth of different skills of the autistic child .

\section{Aims of the study :}

1- Submitting developing program for skills for the autistic child .

2- Measuring the rage of effectiveness of the programs in the growth of integrated skills of the autistic child .

3- Supply the range of possibility of changingthe autistic childs behavior .

\section{Limits of the study :}

Place limits : the study is limited to one autistic child in the stage of kindergarten in zarqa province Jordan .

Time limits : the study was applied in the period between 1.12 2012 To 1.12 . 2015 .

\section{Terminology of the study}

\section{Operational definitions of terminology :}

First : autism is a nervous geological disorder that affects social interactions language communication , child's behavior and his acceptance for learning and training . this Takes many appearance such as, barriers or difficulties in self-care skills, eating and drinking, A Development putting on and taking off clothes going to the bathroom and personal cleanliness and self-secreting .

Second : the integrated program : it is a group of limited regulating stops which basically depends on hypothesis and technician - it includes information and experiences different skills and activities and produced to individuals within a limited period of time which aims to help them to adjust their behavior, new skills which will lead them to achieve the integrated skills and helps them to overcome the problems that they suffer from in life it also aims to achieve the target of the program which is helping the autistic child in grogram which is helping the autistic child in growing raising the integrated skills limited by activities and evaluation means .

Third : the integrated skills, these skills include self - care skills, social skills, typical movements, behavior skills , cognitive skills, pronunciation skills academic skills and all basic needs for daily life .

Method and procedure $\mathrm{s}$ : the procedures include descriptions of the study sample which was applied on the sample individuals, the search steps the statistic design procedures which were followed by the searcher in data processing

The study society : the present study community consists of one autistic child in $\mathrm{k}$. $\mathrm{j}$ kinder garden in zarqa province Jordan . 
The study tools instruments : the integrated scale for autistic child ( prepared by the researcher) the method of designing the scale for the autistic child :

1- The knowledge of the researcher of the literature and studies and previous search s concerned with the area of study also the information about the scales which was designed in this area.

2- The predation of the primary picture of the of the scale in the light of diminutions included in the program.

3- Show the scale to group of specialized arbitration to make sure that the scale items reach the agreement between arbitration up to $84 \%$.

4- The adjustment of the scale in the light of the arbitrators opinions .

5- The integrated scale consists of 172 appendix paragraphs on five levels ( appendix 1 ) Description of the scale for the autistic child the KG stage.

Validity of the scale: the scale : the verification of the sincerity of the scale indicators was as done.

Sincerity of the content : the scale was shown to a group of specialized people in the field of special education and psychology the results showed the agreement of the arbitrations up to $87 \%$ from the range of matching the scale paragraphs to its contents and objectives .

Throng of matching the scale paragraph s to its contents and objectives .
The of the internal consistency: the internal consistency was calculated for the five skills and the result for the self - care skill was (0.78) and the typical movements was $(0.0842)$ the speech skill was $(0.841)$, social skills was ( 0.869) academic skills was $(0.833)$, the table shows the values .

\begin{tabular}{|c|c|c|c|}
\hline Number & The field & $\begin{array}{c}\text { The value } \\
\text { of average } \\
\text { correlation }\end{array}$ & $\begin{array}{c}\text { The level of } \\
\text { significance }\end{array}$ \\
\hline 1 & $\begin{array}{c}\text { Self-care } \\
\text { skills }\end{array}$ & 0.78 & 0.1 \\
\hline 2 & $\begin{array}{c}\text { Typical } \\
\text { movements }\end{array}$ & 0.854 & 0.1 \\
\hline 3 & $\begin{array}{c}\text { pronunciation } \\
\text { and speech }\end{array}$ & 0.841 & 0.1 \\
\hline 4 & Social skills & 0.869 & 0.1 \\
\hline 5 & academic & 0.833 & 0.1 \\
\hline 6 & Total degree & 0.799 & 0.1 \\
\hline
\end{tabular}

It is clear from table one that all the paragraphs in each level on only statistically significant at 0.01 and also the level on the total degree statically significant which indicates that the scale is on a high degree of consistency .

\section{Stability of the scale :}

The verification of significance of the scale stability was made in two ways .

1- The method of computing the reliability coefficient : the reliability coefficient was computed to estimate the value of internal coefficient was computed for the scale . the value of Alfa confection for the scale (0.821) and this is an accepted value and 
ensures the consistency of the paragraph the scale.

2- The method of retail midterm : the scale items were divided into two groups . the first one is of the individual paragraphs . the second group of double paragraphs . the correlation coefficient was computed between the sample in both groups and the correlation coefficient between the sample individuals in two groups ( $\mathrm{R}=0.078)$ and this is high correlation coefficients . table 2

Table 2

\begin{tabular}{|c|c|c|}
\hline Dimension & $\begin{array}{c}\text { Correlation } \\
\text { coefficient }\end{array}$ & $\begin{array}{c}\text { Spearman } \\
\text { brown } \\
\text { equation }\end{array}$ \\
\hline Self-care skills & 0.623 & 0.768 \\
\hline $\begin{array}{c}\text { Behavior } \\
\text { adjustment } \\
\text { skills }\end{array}$ & 0.831 & 0.908 \\
\hline $\begin{array}{c}\text { Pronunciation } \\
\text { and speech }\end{array}$ & 0.630 & 0.773 \\
\hline Social skills & 0.651 & 0.789 \\
\hline Academic skills & 0.612 & 0.759 \\
\hline Total decree & 0.667 & 0.800 \\
\hline
\end{tabular}

It is clear from table 2 that the values of spare man Brown equation is high which indicates that the scale has a high stability degree in the retail midterm.

\section{key of the scale correction :}

each item of the scale items has got two responses (yes) or(no) the child will be given one degree for each (yes) response and zero for ( no) response. The response will be added together for each dimension the to the scale as awhile . resources of building the scales tool (instrument) .

- The researcher benefited from the study in educational literature and studies in this Filed the researcher reviewed autism scale in the $\mathrm{KG}$ stage .

- He also consulted the experts an trainers who wren autistic children .

- The collection of previous studies that was conducted in this field.

- Gathering all programs which were prepared to train autistic children on the internationally integrated scale .

- The time of the program application:

- The application of the program took three years one session weekly and the application took place in the period between 1.2.2013 to 1.2.2015

- The programs sample : the present study has sample of one autistic child at the age of 5-7 old in zarqaprovince - Jordan .

3- Discussion : It is the way used through giving the opportunity for participants to discuss certain situations need to be diseased by participants to ensure the exchange of special ideas and suggested solutions directed by the researchers who used these teaching has as method thrush which the problem solving mother which false the participants to help them to raise their ambitions . 
4- Reinforcement It is a method in which the participants perform the desired behavior ie the reward depends on conditioned the behavior performance. The researcher uses moral reinforcement through the program sessions through the reinforcement of positive ideas and sailable behavior for the nature of participants .

5- Emotional Discharge : It is a method through which the individual is offered help to speak freely and without any restrictions on the written events which might be experiences or motives for emotional conflicts when the individual discharge them the symptoms of being nervous disappear.

The researcher used this technique as a way to help participants to discharge their feeling, experiences motives and conflicts in their life, then they will be helped to overcome these ideas and conflicts and then overcome the technical sides they have got .

6- Epistemological confrontation : It concentrates on the of epistemological and mental sales to determine the pressure importance response more than the environment and its different mothers through the reduction of pressure sharpness that the individual suffers from . if we can change
The way of his thinking towards the situations which causes pressure and eventually considered a response for that situation . through which help the individual to form a new agreement response instead of frustrated and non confident ideas .

Summary of the program sessions (Appendix2) First year pre $-K G$ :

The first session : It aimed at building an interactive relationship between the researcher and the sample. so that the researcher has explained the idea of the program which will be introduced in the coming sessions the researcher has also explained the most important procedures and basic rules which will be followed in the following sessions $\mathrm{He}$ also distributed pictures of the program that contains the dates and the content of each session the name and address and the job of the researcher and phone number and his Email. The place of the sessions application , the dates and numbers of special communications for the researcher, the school and the bus driver. The session ended by thanks to the people.

\section{Second Session :}

The researcher addressed the following title : Definition of autism, reasons and pay ecological affects : The session aimed to know the reasons of autism to participants, the reseal her has opened the dialogue and discussed participants so that they could talk about the reasons that lead to their autism . there 
are different reasons and they differ according to participants . The researcher asked a suasion through the discussion about the psychological effects of disability - some said that they went through very bad psychological cerium standees .

Directly after being disabled and this affected all aspects of their daily life . some families explained about psychological pain through feeling that others look at them as not - ordinary people. some other people began to abandon them social. some others felt that they are isolated people and their hopes and ambitions that they built for themselves were destroyed. And their lives became dependent on the help of others. All these factors affected their feeling and the stability of their lives and they lived in a case of worry and frustration about their future life and being rope less in finding a suitable job for them - The horizon of treatment was also discussed so that some of them travel that there is hope in the treatment through training especially some. Families have got information about care - recovery cases from autism and became an effective member of the society. The researcher discussed the latest medical remedy and behavior programs which was effective in the behavior adjustment and the growth of the autistic child's skills in all fields. Then so many questions were asked about the latest news in the international medical field. The answers for the questions were past pored to the following session .

Third session : Feed book for the first session because of the big number of Qs .

The researcher has explained now for modern searches have reached in medical fields of autism and the effective programs that shows its effectiveness by search centers and universities. The researcher tried to explain to the mothers .

That one autistic child in a family doesn't means that all members of the family will be autistic too so that researcher has noticed that most mothers stopped giving birth to children thinking that all their children will be autistic . Then all causes of autism were discussed specially those related to Harmonic disorders and others .

Fourth Session: The end of the first year ( $4-48$ )addressed self - care programs pronunciation skills and behavior a adjust meant skills. It aimed at the recognition of features of the self - care programs pronunciation .skills, behavior adjustment skills helping the child to pay attention to his basic daily need $s$ independently . performing these missions will allow the child to chive independence in his family life, in addition to gain the ability to perform missions .

The child is supplied with needed abilities to suitable performance in different situation and the mother has the great effect on the program training and 
application .And the presence of an attendant to the child specialized in special education who has get certificates and courses in dealing with autistic children . The researcher has answered the mothers questions . and agreed with her that training and success in any skill need patience and continuous efforts but the end is positive .

Sessions in the second year $(48-96)$ a dressed the continuation of previous skills in addition to academic and social skills .

The sessions aimed at the continuation of previous programs in addition to academic program so that there were new fruits in the first year and in need to continue .The importance of an integration combination in the development of social and academic skills . It is worth to mention that teaching or training one single skill may sometimes need one month of continuous work and the money expenses, for example, In colures teaching unit, the mother does the following she wears address with the color intended to be taught, hang balloons in the house with the same color, and tries to let the kid wear clothes with the same color and also his father does the same. She also serves the food in the same color . she then reminds the child in everything he does with that color. The child then will join a class whose teacher is specialized in special education in addition to the presence of an specialized attendant in these autistic cases . both the researcher and the mother were taking notes from the attendant and the teacher in daily bases and follow up .

The researcher to the teacher the characteristics of this case before entering the kinder gratin. The researcher also discussed with the teacher and the attendant matters related to the application of training so that the training begins by holding the child's hand by mother, teacher or the home trainer and directs the child to integrated respond to achieve success in the direction of the targeted behavior Training should be consistent with all parties in the concerned .

Third year : ( Sessions $96-144$ )The continuation of previous skill in addition to the of the child in first elementary class with ordinary integration pupils. And training on the previous skills . a lot of notes and details needed to complete the raining on academic Discussing with the specialized teacher and the attendant until the child can apply the skills and the present situation of the child and range of preparation of the teacher to be patient and face the new experience Meetings were held .

Between $\mathrm{KG}$ teacher and the attend to take her notes on the case the best ways and the effective programs to deal with the case . The researcher addressed the privacy of the stage phase and range of accuracy and being different from the previous stage and consider it an extension of the previous stage and the techniques of 
dealing with the critical phase and the need to make abnormal efforts optically in dealing with integration and academic teaching for this category

Then the researcher transferred the experiences of $\mathrm{KG}$ teachers and the school teachers the researchers to the $2^{\text {nd }}$ grade teacher after the completion of Its grads, and the case was integrated and still in the integration process. The twenty - third Session : general evaluation of the program the Final Celebration party and distributing of certificate to participants .This aimed at general evaluation for the sessions of the program after its application, the participants stated they had benefitted from ideas diseased and within the Sessions of the program they also expressed their psyches logical satisfaction through their participation in the session .

The school ( Al - Forqan Secondary school in Zarqa) distributed the certificates to the participants .

The researcher thanked the school for the place, The Certificates and the hospitality and transport for participants . He also thanked the participants for their participate in the program and their commitment and presence . A detailed guide ( Handout ) was distributed which included all skill and warning to what must be taken by the family .

The procedures of the Study application The method of the program design .
1- The knowledge of the researcher of the study literature and study and previous searches and the awareness of programmers designed in this field .

2- The preparation of initial image in the light of dimensions in cladded in this program .

view the program by a group of specialized arbitrators to ensure being suitable the matching rate reach eel ( $84 \%$ ) .

Amendment of the program in accordance with the arbitrators opinions .

\section{Sources of Building the program :-}

- The researcher benefited from the educational literature and Studies in this field .

- The Consultation of experts and trainers who work with autistic children .

- previous studies that was conducted in this field .

- All programs internationally prepared for autistic children .

Time of application : The application of the program look three years one Session every week .

The application was between 1/12/2012 To $1 / 12 / 2015$ CE .

The Independent Variables : It is the integrated program which was applied on the sample in accordance with sessions in clouded activities and different fatigues teaching . 


\section{The dependent variables : -}

These are the variables that arise on performance of the Sample in different Skills field, and the response as a result of application of History of the Case : The case started after a year of the birth ( 2008 $\mathrm{CE}$ )the child started to lose the speech repeating one year later the typical movement Started to appear on him. The eye Case Started and he began to throw himself foam the Standing case on the ground directly and strands and refused to be kissed by anymore and if Someone Kissed him he will Keep on crying . He was fond of a toy a dull in the house . he won't go out of sleep unless the doll is with him . when the doll was burnt he started screaming died ........ died, the child lost pronunciation and communication of stewards .

He won't play with others. He couldn't form a two .... Word sentence . He doesn't like shaking hands and keeps flitting with his hades and has got attention deficit .

Treatment previous efforts : The case was dealt with regular medicines and visiting doctors The patient began to move between pronunciation specialists and nerve doctors .

Number of Sessions : The number of Sessions is 144 session one session of 60 minutes a week in addition to the integration of the child in $\mathrm{KG}$ and grade one and two at School. And daily follow up with teachers and taking notes and follow them up .

\section{Training plan :}

1- It included a booting to the family about the importance of training .

2- The use of the house as training aids in all its corners

3- The cooperation with the family in the application of training .

4- The benefit of the mother's being free for her only Son .

5- The participation with the Case in the families different activities .

6- The participation of the family's members with the kids in the program.

7- The benefit of the specialized attendant

\section{The Results of the Study :-}

The result showed the effectiveness of the integrated program in the treatment of an Austic child so that the family, the $\mathrm{KG}$ and the school could apply the progress and follow it up. The results indicate the progress of the child in the following skills fields : In the self - care skills the workmanship reach to a complete degree social skills . The workmanship reached a very high degree and child was initiative to greet and communicate tons with others and the play with children in a selective way. But the response to the orders wasn't less than $70 \%$ of instructions Flitting the hands is still in need of training to abandon. The 
attention deficit became in its low limits . The process of throwing himself on the ground has no more existence. According to the attendant, he became less related to her especially at the beginning of the first semester in the $2^{\text {nd }}$ grade and became jealous about his things and takes care of them .And the reason refers to many factors in the point of view of the researcher One of which that the family especially the mother became fully free to follow up her only sons case .

And Since her husband is a cancer patient which reduces the chance to have another child. So that she studied all the programs she received / about her son's case and she put the statement A teaching aid she designed many training aids to facilitate teaching for her son and she hired an special attendant in the KG phase. The school is specialized in dealing with autistic children and the extended family has appositive role in the success of the program by paying the fees and the school costs and the attendant and their great care on his treatment. That was clear thrush the continuous follow up with the researcher The results of this study agreed with the previous studies results . by building comprehensive treating programs for autistic children ( Gazal's study 2007) it showed the importance of the parent's participation in the coaching program and training on how to deal with autistic child .It is very important in the development of the autistic child's pronunciation and non pronunciation skills and self-care and the control of behavior problems . The result of the study shows that there is a vital effect to share parents in the development of self - care skills and the reduction of autism symptoms on the members of the study .

The study (of Eric, et . 2016) addressed and showed the effectiveness of the pronunciation training program on $\mathrm{KG}$ autistic children and the importance of the family participation in the execution of the program . In the study of Thebe ( 2004 ) he concluded that the program was prepared to devalue the social skills and communication skills as well as the self independence skills in notable rates And non - amendment behavior of autistic child. The researcher Sees that the use many and different methods in the program application has a great positive in developing Self - care skills for autistic children and this result was Supported by ( Do babnah\& parish , 2016) which proved the importance of family training on the early interferences in the treatment of autistic children and the Knowledge of the family of the critical stages the autistic children go Through. This result was also supported by ( unlu , \&vuran )which addressed the mothers training effects on the positive and fast results for the autistic child response for the program prepared to adjust some behavior. This result was also Supported by ( Hodgetts, et al ,2015 )The Study showed the importance of details of the autistic Kids families concerning training , financial and psychological 
Support for them and their families This result was also Supported by AL- Jarehi (2004) which also proved the effectiveness of the behavior amendment program in qualify ins and treating kids with autism disorder . because behavior treatment depends on the technique of behavior management in order to get rid of the unaccepted behavior and the reduction of unaccepted behavior and typical repetitive actions . and other forms of behavior, The principle of reward and punishment is considered a major principle in this technique with the aim of developing and rein for mint positive behavior and reducing and exclusion of negative behavior. The success of behavioral remedy was clear with those children encouraging of and communication skills social skills, acquisition and self-care skills as well. In addition to epistemological skills .

The researcher also Sees the use of teaching aids by playing and the use of physical exercises has an effective role in the success of the program .This result was Supported by AL- Hayyan ( 2007 )and the program achieved positive results on the diminutions of the Four behavior list of appearances : Emotional disorders, Social disorders, language disorders and typical ( behavioral patterns. This playing is considered a good material to solve Some problems and behavioral disorders for autistic children So it was concentrated on by Some studies which work on behavior amendment . This result was also supported by Tawfeeqs, study ( 2012 ) that it the result showed effectiveness in using playing to reduce both aggressive and introvert behavior. The result was also Supported by Khattab's study ( 2012 )the result showed that playing just like most kinds of treatments psychological methods which takes character as a whole and generally affects, The researchers sees that the variety of methods of treatment and the use of training and qualifying methods and the educational and Social interaction has got a great effect on the success of the program . AL- Qahtani study ( 2015 )addressed the effective ness of the coaching program which depends on playing . on the growth of daily skills of the special needs kids As Mustafa 's study ( 2015 ) supported the effectiveness by art in developing social skills for autistic children The study of AL- Khav'an (2015).

This result proved the effectiveness of a training program for $\mathrm{K} \mathrm{j}$ teach ers and a course of improving the transfer from $\mathrm{KG}$ to special centers for autistic children . The researchers sees that Some of the reasons of the success of the program is the suitable environment provided by Al - Forqan schools which provided the transport . the place and hospitality for participants and their family - The issue of certificates to the participants and facilitied the mission of the researcher and the participans by using all school facilities, library, labs and playground etc. And this greatly appreciated by the researcher . The 
researcher also sees that some of the helping factors to the success of the program the specialised volunteers who work in social filed and $\mathrm{KG}$, the methods of dealing with autistic children, the training of different skill. Some of them hold academic degrees in special education . These results don't differ from the results of previous studies which was viewed by the researcher All studied agreed with the results of this present study. The effectiveness of the targeted Categories in these programs . The researcher Sees that Some of the helping factors to the success of the program is the availability of specialized volunteers in teaching autistic children. There are specialized teachers in special education in school and Kinder garten . They love to work these Categories . The administration of the school and $\mathrm{KG}$ helped to provide to provide the place for training and the acceptance suitable of the idea of integration .

$\mathrm{Al}$ - Forqan school provided the needed support such as programs, machines needed by this category these programs weren't different (devices) from the results of previous studies that the researcher has got the chance to review . All these Studies agreed with the results of this present study in the effectiveness of treatment programs for autistic children The Searcher Sees that the results they have reached could by explained as the following : 1- This study is
Considered the first Study of its Kind in the region So it was greatly welcomed by the family .

2- The relationship between the researcher and the Family through their social and commercial relationship as they are shareholders in the school which enhanced the positive relationship to accept the idea of training and response and the discussion freely .

3- The financial and moral support supplied by the extended family of the autistic child .

\section{- The Study Recommendations .}

1- The necessity to supply and develop teaching aids and thchgnigues for autistic children .

2- The modernization of programs in different field for autistic children .

3- The modernization of laws and Systems that keep the rights of this category .

4- The encouragement of searches and studies that deals with Communication programs and teaching aids and assistance .

5- The training of the workers in societies and Contras on the application of different programs .

6- The spread of programs and waking it available for workers in centers which leads to the advancement of this category . 
7- The spread of Cultural awareness through the different Media about the importance of these integrated programs .

\section{Research Proposals :}

- The effectiveness of attaining program in developing the Self Concept for autistic child.

- A proposed Visualizing to the special resources for autistic children .

- The effectiveness of a social program in verbal Communication skills for autistic children and non- verbal .

\section{References}

- Tawfiq Sam'ei (2012) physical Education as a treatment activity for autistic children, unpublished Master letter - Farhan Abbess university - Algeris

- Al - kharan, Hayazaid Magazine Volume (2015) Effectiveness a training program for $\mathrm{KG}$ teachers to improve the trans for of KG kids special centers to autisim disorders children .

- Specialized International Educational Magazine volume (4) Khattab , RafatAwadhSaeed ( 2012)

- (NO3) Effectiveness, Attainins program depends on theoretical mind Concepts to develope social media in the Social interaction for autistic Kids Psychological Cho aching Magazine ( NO3) Saudi Arabia .

- Al - Khufash, SehamRiad (2013) A training program in the treatment of sleep problems for children autisinsm disorders . Epcialised International Magazine volume (2) ( NO10) .

- Do gestanthi , Bali's Ismail ( 2011) The use of Portrayed Activities Table.

- An approach to the acquaintance of life skills of KG children- At Quds Open University for Research s and Studies . Volume (22).

- Deep , Ra'ed (2004) Design of a training program to develop social, Communicational and independence skills for autistic children and the measurement of a doctorate unpublished letter - the university of Jordan , Jordan.

- Thebe , Ra'ed (2013) The synch cosmetic properties for the Saudi picture of gilt am scale diagnosis of autisism (GARS2) Studies magazine Volume (40) appendix (1) The University of Jordan , Jordan .

- Al - Zaharani , Khalid Bin Mussa'ed (2012) The effectives of the use of behavioral pros ram to reduce the disability appearance $\sin$ social Interaction for a Sample of autistic adults Unpublished Master letter , Um Aqura University . Saudi Arabia .

- Al - Sarttawi, Abdal - Aziz Mustafa (2015) I can Indicators of sincerity and stability to discover autisism in United Arab Emirates , Arab Childhood Magazine Volume (16)No ( 62 ) UEA.

- Salama , Ra'beeh Shukri (2005) , Autisism the riddle that Confused Dar $\mathrm{Al}$ - Nahar 
- Arab References

- Al - shamalia , Mohamad Waleed (2012) The effectiveness of regular teaching to the ( SPCTRA)

- Program to improve daily life skills for autistic Children unpublished Master letter Damascus University - Syria .

- Ammar, Majid Al-Sayyed ( 2005 ) Autisism disability between diagnosis and differtial diagnosis T1. Cairo Zahral ,- Al - sharq Library .

- Gazal, MajdiFathi ( 2007 ) The Effect liveness of a training program in the development of social skills to asample of autistic children in Amman city - An unpublished Master letter - university of Jordan, Jordan .

- Al - Qahttani , HananBiut Mubarak ( 2015 ) The of effectives of a teaching and training program for the daily skills of a sample of special needs children in Saudi Arabia - The specialised International Magazine volume ( 4 ) No (4) .

- Mustafa , Dina ( 2015 ) Art therapy and the development of Social skill for children of autism disorders. Especialised International Educational Magazine volume ( 4 ) No (4) .

- Carothers, D. \& Taylor, R. (2004). How teachers and parents can work together to teach daily living skills to children with autism, Journal; Peer, Reviewed, Journal Focus on Autism and Other Developmental Disabilities, Vol. (19), No. (2), pp. 102-10.
- Carpenturi\&morgan (1996). Adaptive and intellectual functioning in autistic and no autistic retarded children, Journal of Autism and Developmental Disorders, Vol. (26), No. (6), pp. 611620.

- Dababnah, s.\& Parish, s.(2016). Feasibility of an empirically based program for parents of preschoolers with autism spectrum disorder .Autism(SAGE Journal, vol.20 No.1.pp 85-95.

- Eric.J., Dwight, I, Katie ,Bi, Luke m, Brain, A, \& Samuel , L.(2016).The questions verbal children with autism spectrum disorder encounter in the inclusive preschool classroom. Autism(SAGE Journals). Vol(20) No(1).pp.96-105.

- Hodgetts, s.\&Zwaigenbaunl, 1. \& Nick olas, $\mathrm{D}(2015)$. Profile and predictors of service needs for families of children with autism spectrum disorders. Journal of Autism(SAGE Journals), vol.19(6), pp673-683.

- Hus Bal, v.\& Kim, s.\& Cheong, D.\& Lord, c.(2015).Daily living skills in individuals with autism spectrum disorder from 2 to 21 years of age. Autism (SAGE Journals), vol. 19(7).pp 771-775.

- Unlu, E.\&vuran, s.(2012).case study:Trainingamother of child with autism on how to provide discrete trail teaching. International Journal of Early Childhood Special Education (INT-JECSE), 4(2),PP 95-103 